\title{
Quality specifications in postgraduate medical e-learning: an integrative literature review leading to a postgraduate medical e-learning model
}

\author{
R. A. De Leeuw ${ }^{1 *}$, M. Westerman², E. Nelson ${ }^{3}$, J. C. F. Ket ${ }^{4}$ and F. Scheele ${ }^{1,2}$
}

\begin{abstract}
Background: E-learning is driving major shifts in medical education. Prioritizing learning theories and quality models improves the success of e-learning programs. Although many e-learning quality standards are available, few are focused on postgraduate medical education.

Methods: We conducted an integrative review of the current postgraduate medical e-learning literature to identify quality specifications. The literature was thematically organized into a working model.

Results: Unique quality specifications $(n=72)$ were consolidated and re-organized into a six-domain model that we called the Postgraduate Medical E-learning Model (Postgraduate ME Model). This model was partially based on the ISO-19796 standard, and drew on cognitive load multimedia principles. The domains of the model are preparation, software design and system specifications, communication, content, assessment, and maintenance.

Conclusion: This review clarified the current state of postgraduate medical e-learning standards and specifications. It also synthesized these specifications into a single working model. To validate our findings, the next-steps include testing the Postgraduate ME Model in controlled e-learning settings.
\end{abstract}

Keywords: E-learning, Distance learning, Education, Medical education, Medical e-learning, Quality model, Integrative review, Postgraduate medical education

\section{Background}

E-learning plays a prominent role in conventional education, adult education, and medical training because of its flexibility, broad resource-sharing capacity, and costeffective scalability [1]. E-learning has become central to medical education, and web technologies offer valuable new opportunities for both under- and postgraduate medical education [2]. E-learning also offers participants' an advantage in that they can choose a comfortable and accessible place and time to study, which is important in postgraduate and continuous medical education [3].

There are many studies comparing e-learning methods. However, one of the problems is that the results of studies

\footnotetext{
* Correspondence: r.deleeuw@vumc.nl

${ }^{1}$ Athena Institute for Trans-disciplinary Research, VU University Amsterdam,

De Boelelaan 1118, Amsterdam $1081 \mathrm{HZ}$, The Netherlands

Full list of author information is available at the end of the article
}

directly comparing technology-assisted education with traditional teaching often conflict and often do not demonstrate or propose best practices $[4,5]$. Critical evaluation of the quality and efficiency of e-learning is warranted [6]. Therefore, there is a need to develop a consensus-based quality assurance standard for postgraduate medical e-learning $[7,8]$.

It is known that e-learning should be targeted to the needs of the specific audience (in this case postgraduates) $[9,10]$. The success of e-learning programs has also been linked to the use of a theoretical framework or a learning theory [11]. Standards for e-learning exist and have been evaluated [12].

Although learning theories are broad and diverse, there is progressive agreement about the psychological fundamentals [13]. Previous research suggests that the constructivist approach (founded by Jean Piaget, among 
others) is compatible and appropriately designed for elearning. According to this theory, humans are active learners and construct new knowledge based on prior experiences and interactions [14]. An example is problembased learning, which has been shown to be effective in medical education $[15,16]$. Another theory based on the constructivist approach is the cognitive load theory (CLT) developed by Sweller [17]. The constructivist approach also forms the foundation of the cognitive theory of multimedia learning, a well-evaluated learning theory developed by Mayer [18]. This theory has been specifically adjusted for e-learning, and is believed to provide a good basis for an e-learning standard [18]. These theories are not elaborated here. However, it is important to remember that learning theory, not technology, should guide the design and content of e-learning.

Standards for e-learning exist [12], but are often isolated to a specific sector of the industry for which they were developed [19]. There are many industrial standards in education, often published by organizations such as the American Council on Education and the European Association of Distance Teaching Universities [20]. Several organizations have made progress in developing international industrial standards for universities, including the Open e-Quality Learning Standards and the Leonardo DaVinci program [21, 22].

The most common formal standard in use is the ISO/ IEC 19796-1 [23]. This standard was issued by the International Standardization Organization (ISO) in 2005, and contains the Reference Framework for the Description of Quality Approaches (RFDQ), a framework supported by the European Quality Observatory [24]. Stracke implemented this standard and concluded that it was not only the first quality standard for learning, education, and training, but was a valuable instrument for sustained quality development in e-learning [23]. Little tested two higher education quality standards or rubrics, in professional continuous nursing education in 2009 [25]. The College of Public Health Online Course Standards and the Quality Matters Peer Course Review Rubric were evaluated, and although they look hopeful, little is known about their actual effectiveness. The Quality Matters rubric is not publicly available, making evaluation even less accessible.

Existing literature fails to clarify the methods and strategies used to evaluate the quality of postgraduate medical e-learning. As Clark noted in his well-respected book E-Learning and the Science of Instruction, the target audience should be the first thing considered when designing an e-learning program $[9,10]$. Although undergraduates and postgraduates may learn in the same way, adult learning theories suggest their learning strategies and capacities might be dissimilar. Therefore, we focused our review on our target audience: postgraduates and physicians bound to continuous medical education. Ellaway et al. began this process in 2008 by describing a two-part guideline for e-learning in medical education. Although the guideline was not specifically aimed at postgraduate medical education, it served as a foundation for further research [16, 26]. The previously mentioned standards and the Quality Matters Rubric look promising, but are all aimed at different target audiences [25]. The ISO standard (ISO/IEC 19796) covers a lot of domains, but lacks detail regarding their application [27].

It is difficult to establish quality control practices for e-learning materials [28], yet this is an important problem in postgraduate medical education where the quality of training directly influences patient care [29]. Therefore, as technological innovations reshape medical education institutions, the question of quality assurance is at the forefront of university leadership concerns worldwide [30]. In 2010, Cook et al. reiterated the primary importance of defining quality standards in medical education. In their Second Flexner Report, they identified standardization as a key goal for improving medical education [31]. We believe that it is important to establish a testable quality assurance model to improve the uptake of e-learning and motivate continuous medical learning [5]. This review will add to existing literature by providing an integrative literature review and a working model of quality assurance standards in postgraduate medical e-learning.

\section{Methods}

We performed an integrative review to identify and critically evaluate qualitative and quantitative literature associated with current postgraduate medical e-learning quality assurance. We used the updated integrative review methodology developed by Whittemore et al. [32] This method consists of three steps: 1) a systematic search combined with at least one nonsystematic search method; 2) data evaluation comparing study models and quality scores; and 3) data analysis. During data analysis, we compared individual quality items, clustered them, searched for contrasts and comparisons, discerned patterns, and built an overview of the domains.

\section{Definitions \\ E-learning}

An approach to teaching and learning, representing all or part of the educational model applied, based on the use of electronic media and devices as tools for improving access to training, communication, and interaction and that facilitates the adoption of new ways of understanding and developing learning [33]. In practice, the definition includes any digital content made to teach and distributed physically or online. 


\section{Quality}

To date, there is no consensus definition of quality. However, a high-quality product is generally defined as one that meets consumer-defined specifications, delights the consumer, consistently meets the standard that the producer has set for itself, and leads to customer satisfaction. Producers should be able to assure this quality [30,33].

\section{Postgraduate (and continuous) medical education}

Any form of learning aimed at medical professionals who have graduated from formal training and residency, or used by medical professionals a part of continuous learning to maintain their competency and develop new knowledge [34].

\section{Standards and specifications}

A standard is a set of specifications that guide an elearning author in developing an e-learning program. A specification is a specific item that is addressed within the standard [17].

\section{Step 1: Systematic literature search}

The primary search terms were distance learning (and all synonyms) [35] and quality (and all synonyms). We conducted the search on May 2, 2015. We searched ISI/Web of Knowledge, PubMed, EBSCO/Cinahl, EBSCO/PsycInfo, and EBSCo/ERIC (Table 1). Google Scholar was also searched, despite debate on its added value [36].

\section{Inclusion criteria}

Included articles were peer-reviewed and published in the English language between 1970 and May 2015. The articles had to describe and evaluate specific e-learning characteristics in postgraduate or continuous medical education. The search was kept broad and selection was made on postgraduate medical education manually after reading the titles, abstracts, and the full text (if necessary).

\section{Exclusion criteria}

We excluded dissertations, conference abstracts, and articles comparing e-learning with other forms of learning without describing the quality specifications used.

After selecting the titles and abstracts, we sampled 40 random abstracts for independent evaluation by a second (MW) and third author (FS). If there was no consensus, three authors participated (RL, MW, FS) in a discussion until consensus was reached on whether or not to include the article.

Table 1 Databases searched and corresponding search strings

\begin{tabular}{|c|c|}
\hline Database & Search string used \\
\hline PubMed & $\begin{array}{l}\text { (((('assessment[Title/Abstract] OR criteria[Title/Abstract] OR metrics[Title/Abstract] OR characteristics[Title/Abstract] } \\
\text { OR measurement[Title/Abstract] OR evaluation[Title/Abstract] OR "Quality Control"[MeSH] OR "Quality Improvement"[MeSH] } \\
\text { OR "standards"[Subheading] OR "Guideline"[Publication Type] OR "Guideline Adherence"[MeSH])) OR quality[Title/Abstract]) } \\
\text { OR principles[Title/Abstract])) AND (("Education, Distance"[MeSH] OR e-learning[Title/Abstract] OR electronic } \\
\text { learning[Title/Abstract] OR distance education[Title/Abstract] OR technology-enhanced learning[Title/Abstract] OR } \\
\text { tele-learning[Title/Abstract] OR web-based learning[Title/Abstract] OR web-based education[Title/Abstract] OR } \\
\text { internet-based learning[Title/Abstract] OR computer based learning[Title/Abstract] OR computer-assisted } \\
\text { instruction[Title/Abstract] OR distance learning[Title/Abstract] OR online learning[Title/Abstract] OR (("Learning"[MeSH] } \\
\text { OR "Education, Professional"[MeSH]) AND ("Computer Communication Networks"[MeSH] OR "Computer-Assisted } \\
\text { Instruction"[MeSH])))) }\end{array}$ \\
\hline ISI/Web of Knowledge & $\begin{array}{l}\text { (assessment OR criteria OR metrics OR characteristics OR measurement OR evaluation OR standards OR quality OR } \\
\text { principles) [TI] AND (e-learning OR (electronic learning) OR (distance education) OR (technology-enhanced learning) } \\
\text { OR tele-learning OR (web-based learning) OR (web-based education) OR (internet-based learning) OR (computer } \\
\text { based learning) OR (computer-assisted instruction) OR (distance learning) OR (online learning)) [AB] }\end{array}$ \\
\hline EBSCO/Cinahl & $\begin{array}{l}\text { (assessment OR criteria OR metrics OR characteristics OR measurement OR evaluation OR standards OR quality OR } \\
\text { principles) [AB] AND (e-learning OR (electronic learning) OR (distance education) OR (technology-enhanced learning) } \\
\text { OR tele-learning OR (web-based learning) OR (web-based education) OR (internet-based learning) OR (computer } \\
\text { based learning) OR (computer-assisted instruction) OR (distance learning) OR (online learning)) [AB] }\end{array}$ \\
\hline EBSCO/Psychinfo & $\begin{array}{l}\text { (assessment OR criteria OR metrics OR characteristics OR measurement OR evaluation OR standards OR quality OR } \\
\text { principles) [AB] AND (e-learning OR (electronic learning) OR (distance education) OR (technology-enhanced learning) } \\
\text { OR tele-learning OR (web-based learning) OR (web-based education) OR (internet-based learning) OR (computer } \\
\text { based learning) OR (computer-assisted instruction) OR (distance learning) OR (online learning)) [AB] }\end{array}$ \\
\hline EBSCO/Eric & $\begin{array}{l}\text { (assessment OR criteria OR metrics OR characteristics OR measurement OR evaluation OR standards OR quality OR } \\
\text { principles) [AB] AND (e-learning OR (electronic learning) OR (distance education) OR (technology-enhanced learning) } \\
\text { OR tele-learning OR (web-based learning) OR (web-based education) OR (internet-based learning) OR (computer } \\
\text { based learning) OR (computer-assisted instruction) OR (distance learning) OR (online learning)) [AB] }\end{array}$ \\
\hline Google Scholar & $\begin{array}{l}\text { All in title: (assessment OR criteria OR metrics OR characteristics OR measurement OR evaluation OR standards OR } \\
\text { quality OR principles) AND ((e-learning OR (electronic AND learning) OR (distance AND education) OR } \\
\text { (technology-enhanced AND learning) OR tele-learning OR (web-based AND learning) OR (web-based AND education) } \\
\text { OR (internet-based AND learning) OR (computer AND based AND learning) OR (computer-assisted AND instruction) } \\
\text { OR (distance AND learning) OR (online AND learning)) }\end{array}$ \\
\hline
\end{tabular}




\section{Step 2: Data evaluation}

We aggregated the selected studies that met the inclusion criteria, flagging those with an unclear method. The aggregate was graded according to criteria adapted from the levels of evidence model of the Oxford Centre for Evidence-Based Medicine (Table 2). Our adaptation consisted of the addition of grade 6, indicating an unclear method. We flagged a study as unclear if it did not fall into any of the five existing categories.

We used the two-tier data evaluation strategy developed by Wittemore et al. to grade the quality of each item. Levels 1, 2, and 3 were identified as high quality (tier 1 ), and 4 and 5 as low quality (tier 2) [32]. We removed grade 6 studies from the analysis.

\section{Step 3: Data analysis}

After aggregating the studies and grading the papers, we analysed each item for common themes and contradictory findings. If items conflicted, we rejected the lower quality study in favor of the higher quality study. We categorized the items according to the ISO/IEC 19796-1 domains, and then generated new themes for items that did not fit the established domains.

\section{Results}

\section{Primary selection and analysis}

The literature search identified 10,732 articles. Searching Google Scholar gave us access to unanticipated databases such as the Emerald, IEXEE, and Editlib, as well as journals that were not registered with the other databases (International Journal of Information and Educational Technology, Journal of E-Learning and Knowledge Society, Applied Soft Computing, International Educational E-Journal, and Journal of Theoretical and Applied Information Technology). We then manually reviewed the identified studies.

After applying inclusion and exclusion criteria, 884 eligible titles remained. Eligible abstracts were reviewed and final selection criteria were refined as described in the Methods section.

Table 2 Adapted Oxford Centre for Evidence-Based Medicine levels of evidence

\begin{tabular}{llc}
\hline Level & Design & Tier \\
\hline 1 & $\begin{array}{l}\text { Systematic review of randomized controlled } \\
\text { trials or individual randomized controlled trial }\end{array}$ & high \\
2 & $\begin{array}{l}\text { Systematic review of cohort studies or individual } \\
\text { cohort study }\end{array}$ & high \\
3 & $\begin{array}{l}\text { Systematic review of case-control studies or } \\
\text { individual case-control study }\end{array}$ & high \\
4 & Case-series & low \\
5 & Expert opinion & low \\
6 & Unclear method & low \\
\hline
\end{tabular}

In total, 36 articles met the final selection criteria (see Fig. 1), representing quality items in postgraduate medical education literature. Of these, 15 were original case reports and expert opinions; 13 were reviews of previous case reports and expert opinions; five were randomized controlled trials; and two were meta-analyses (Table 3). Collectively, these articles represented 16 high tier articles (Oxford Centre for Evidence-Based Medicine levels 1,2 , and 3) and 20 low tier articles (levels 4 and 5). The publication dates ranged from 1995 to 2015.

\section{Sub-selection and analysis}

After consolidating duplicates for quality specifications (440 in total), there were 72 unique quality specifications remaining. We categorized these specifications according to the seven ISO 19796 domains, combined them, and renamed them if necessary. This produced a model with six final domains, which we called the Postgraduate Medical E-learning Model (Postgraduate ME Model; Fig. 2). In the following paragraphs, we have defined the domains and provided examples from the literature.

1. Preparation: This step should be performed before designing and building the e-learning platform.

Twelve articles described the importance of knowing the end users [23, 36-46]. Preparation is a two-step process. First, one must define the platforms used by different types of end users and their expectations of the e-learning platform. If the end users' level of knowledge is known, the e-learning strategy can be designed appropriately. Special functionalities for individuals with learning disabilities can also be incorporated if applicable. Cook et al. described this step as a part of the needs analysis [10]. If possible, learning should be adapted to the audience's motivational level, skills, and expectations. Curry et al. [47] and Olson et al. [20] emphasized the importance of selecting e-learning authors based on subject matter expertise. They suggested that academically qualified people must actively participate in development and training to improve e-learning. Four articles advised readers to allocate time to accurately budget and plan for the expected costs [23, 41, 44, 48]. Budgets and policy statements should reflect commitment to the program. Seven authors agreed on the positive effect of planning, describing objectives and expectations, and placing these in a timeline to maximize efficiency $[7,23,36$, 37, 39, 40, 49]. Cook et al. [50] identified potential barriers to implementation, and Olson et al. [20] advised readers to develop a marketing plan for reaching end users. Curry [47], Wong [51], and Sowan [39] advocated efficient e-learning that 


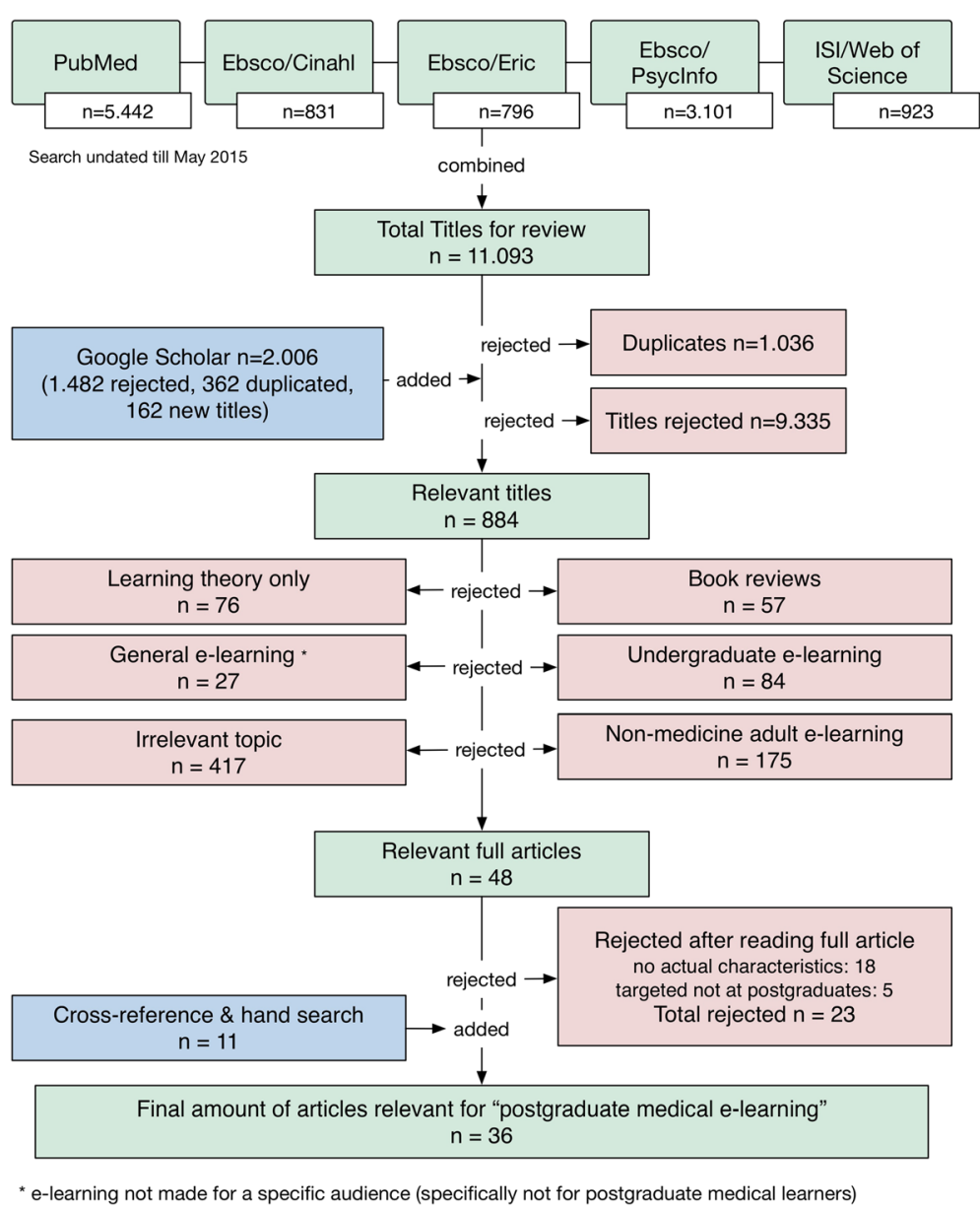

Fig. 1 Flowchart of the literature search results

saves the user time, compared with other forms of learning.

2. Design: This depends on a series of difficult choices that include the types of hardware and software that best fit end-users' needs. Although, hardware and software are very different, most articles described these in one section. In several articles $(n=5)$, authors stressed the importance of reliability and emphasized that the combined hardware and software system should be tested and iterated to meet end-user design requirements [7, 23, 39, 42, 49]. Testing should include different browsers and different monitors with varying resolutions, as well as different hand-held devices if a mobile-based platform is developed.

Most $(n=14)$ articles discussing software design focused on ready access to the e-learning platform. Access should be fast, easy to find, and always available; the platform should have a short loading time, and should provide reliable online access to all external links [7, 36-40, 45, 46, 48, 49, 52, 53, 70]. A secure connection is also important to support the privacy and legal requirements, copyright rules, and intellectual property issues [23, 39, 44, 49]. Lewis et al. [52] urged readers to be mindful of the basics such as grammar and spelling. Cook et al. [6] advised piloting e-learning websites before publishing them, and Bangert [46] advised the use of a variety of learning environments. Yavner et al. [53] wanted to give users maximum control over navigation, an approach that Mayer later challenged [54]. Navigation and layout are important design elements. Navigation should be user friendly and intuitive with a "less is more" design strategy. The design should be visually pleasing, adhere to the principles of excellent website design, and use reusable learning objects for a standard look and feel $[37,45]$. Four articles provided a minimal set of pages/functionalities: glossary of terms, frequently asked questions, concept map, references cited, abbreviation key, and labelled diagrams $[36,45,55,56]$. 
Table 3 Articles used for the postgraduate medical education model identified in the literature search

\begin{tabular}{|c|c|c|c|c|c|}
\hline First author & Year & Type of study & Domains discussed* & Evidence tier & Reference \\
\hline Khoiny & 1995 & Expert opinion & 1 & Low & {$[57]$} \\
\hline Kim & 1999 & Systematic review & $1,2,4,5,6$ & High & [72] \\
\hline Sekikawa & 2001 & Expert opinion & 2 & Low & [73] \\
\hline Doyle & 2002 & Expert opinion & 2,3 & Low & [74] \\
\hline Jha & 2002 & Case study & $1,2,4$ & Low & {$[75]$} \\
\hline Minasian & 2002 & Expert opinion & $1,2,5,6$ & Low & [55] \\
\hline Cook & 2004 & Review & $1,2,3,4,5,6$ & high & [6] \\
\hline Olson & 2004 & Review & $1,2,3,4,5,6$ & high & [20] \\
\hline Knight & 2004 & Expert opinion & $1,2,3,4,5,6$ & low & [48] \\
\hline Casebeer & 2004 & Trial & $2,4,5$ & high & [44] \\
\hline Curry & 2005 & Expert opinion & $1,2,4,5,6$ & low & [47] \\
\hline Bangert & 2005 & Case study & $2,3,4,5$ & low & [46] \\
\hline Garde & 2007 & Case study & $3,4,5$ & low & [43] \\
\hline Maor & 2007 & Review & 3,4 & high & [45] \\
\hline Posel & 2009 & Review & $1,2,4,5,6$ & high & [66] \\
\hline Casimiro & 2009 & Review & $2,4,5$ & high & [71] \\
\hline Cook & 2010 & $\mathrm{RCT}$ & $3,4,5$ & high & [50] \\
\hline Wong & 2010 & Review & $1,2,3,4,5$ & high & [51] \\
\hline Mayer & 2010 & Review & 4 & high & [54] \\
\hline Short & 2010 & Review & $2,3,4,5$ & high & [64] \\
\hline Alexander & 2010 & Expert opinion & $1,2,3,5,6$ & low & [37] \\
\hline Friedlander & 2011 & Review & 4 & high & [62] \\
\hline Chang & 2011 & Case study & $1,2,3,4$ & low & [49] \\
\hline Issa & 2011 & Cohort study & 4 & low & [63] \\
\hline Mounsey & 2012 & $\mathrm{RCT}$ & 4 & high & [60] \\
\hline Raymond & 2012 & Expert opinion & $1,3,4,5$ & low & [41] \\
\hline Sowan & 2013 & Expert opinion & $1,3,4,5$ & low & [39] \\
\hline Mhouti & 2013 & Review & $1,3,4,5$ & high & [58] \\
\hline Bluestone & 2013 & Meta-analysis & 4,5 & high & [61] \\
\hline Gordon & 2013 & $\mathrm{RCT}$ & 4 & high & [38] \\
\hline Shaw & 2014 & Case study & $2,4,5$ & low & [76] \\
\hline Lewis & 2014 & Review & $1,2,4,5$ & high & [52] \\
\hline Yavner & 2014 & Expert opinion & $1,2,4,5,6$ & low & [53] \\
\hline Lau & 2014 & Review & $2,4,5$ & high & [42] \\
\hline Davids & 2014 & $\mathrm{RCT}$ & $2,4,5$ & high & [56] \\
\hline Cook & 2015 & Review & $1,2,3,4,5,6$ & high & [10] \\
\hline
\end{tabular}

$R C T$ randomized controlled trial

Domains: 1. Preparation, 2. Design and system, 3. Communication, 4. Content, 5. Assessment, 6. Maintenance

Olson et al. [20] and Lau [42] suggested choosing appropriate, intuitive, and user-friendly hardware devices that advise the learner of the skills and technology required for success. Desired learning outcomes should drive the choice of technology. Khoiny [57], Garde et al. [43], and Mhouti et al. [58] described the importance of the environment where the e-learning is used. The physical setting should be a stimulating and motivational place to learn.

3. Communication: This includes all forms of internal user-oriented communication and external expertoriented communication. Articles included in our 


\section{6 domains of the Postgraduate ME Model}

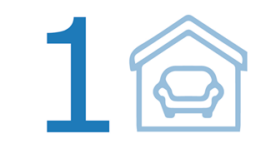

PREPARATION

A. Know the users

B. Identify the authors

C. Plan the costs

D. Make a timeline with objec-

tives, expectations, barriers and marketing

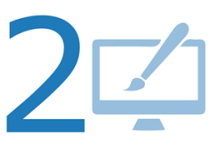

DESIGN \& SYSTEM

A. Software, choose depending On usability, flexibility and test it B. Easy navigation and appropriate, simple layout C. Minimal set of pages D. Choose a device and advice D. Choose a device E. Access should be easy, fast cave, stable, online and ast, save, stable, online and meet

about the appropriate learning environment

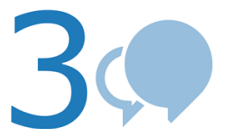

COMMUNICATION

A. Inform users about learning objectives, costs and support

B. Provide user-author contact and live interactivity

with the expert

C. Identify authority of

authors

D. Collaborate between users

Fig. 2 Postgraduate medical e-learning specifications model

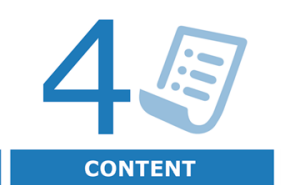

A. Cognitive load multimedia principles*

B. Interactive learning

C. Provide time

C. Use a standard

E. Give responsibility to the user

F. Reminders

G. Rewards

H. Problem-based learning

I. Exercises

J. Content overview

$\mathrm{K}$ - Use multiple Learning styles

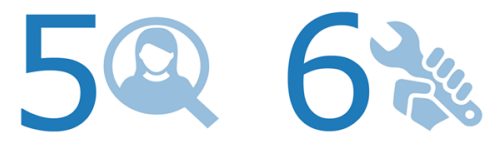

ASSESSMENT

MAINTENANCE

A. Evaluate user

C. Continue to provide outside and costs

knowledge and access after C. Update

C. Update review provided descriptions of several forms of communication, including: (i) communication about the program that informs the user about learning objectives, costs, and support options; (ii) communication that allows users to contact the faculty/course authors; and (iii) communication between users as they collaborate on coursework. Several articles $(n=8)$ emphasized the second form of communication, recommending opportunities for live interaction with experts/authors, possibly in a group context [38, 41, 43, 45, 55, 59]. The credibility of the authors should be well established, and should include the authors' credentials and disclosure of sponsors and conflicts of interest.

4. Content: This is the aggregate material used to build the lessons (e.g., words, images, videos). Content was a central theme in the articles we reviewed. Problem-based learning was favoured by 13 articles as the best way to incorporate motivation and better understanding $[7,15,40,43,46-48,52,56-60]$. Introducing interactivity to encourage higher-order thinking was also important ( $n=16$ articles) [23, 36, 39-41, 45-47, 51, 52, 56-59, 61]. The user should be provided with time and impetus to learn with as little stress as possible and made responsible for the learning process to create a feeling of belonging, and the platform should provide learning exercises $[7,41,46,48,61]$. Learning modules should end with summaries, consist of short paragraphs, state a timeline, and use milestones [23, 36, 39, 41, 43, 44, $46,47,49,50,59]$. Lewis et al. [52] emphasized the use of educational standards, and most other articles suggested using cognitive load principles. Cognitive load principles are described in the Discussion. Bluestone et al. [61] advocated for reminders in e-learning systems, and Friedlander et al. [62] and
Cook [59] suggested incorporating rewards and reinforcements to maintain motivation.

5. Assessment: This refers to all of the possible ways to test end users and formalize their knowledge gain. Almost all of the articles prioritized assessment and feedback on performance. Seventeen articles described assessment as most effective when used in a direct, continuous, and personalized way $[7,15$, $23,36-38,40,41,45-47,50-52,56,58,63]$. Selfassessment was also an important part of learning [7, 23, 36, 39, 40, 43-45, 47, 54, 57, 59]. Additionally, Lau [42], Short et al. [64], and Wong et al. [51] stressed the importance of continuing to provide the e-learning software and associated tools after the end of the course. Cook et al. focused on the importance of assessing user experience and satisfaction [50]. Assessment is also a way of evaluating learning outcomes [10].

6. Maintenance: This includes the steps taken to avoid the loss of knowledge after a user finishes the e-learning process. Maintenance also includes reliable long-term access to the platform to allow an end user to return to the platform. Maintenance-related articles $(n=10)$ described the importance of evaluating a platform's user experience, effectiveness, usability, and cost $[7,23$, 36-38, 40, 44-46, 59]. Technical maintenance included protecting and verifying hyperlinks. Several articles $(n=6)$ emphasized that modifications to e-learning programs should be enabled and updated, and those proven to be unsuccessful removed [7, 23, 37, 38, 44, 45]. Elearning developers should also estimate the reusability and sustainability of new platforms, as these factors are important in the platform's maintainability [10]. 


\section{Discussion}

We identified 72 features as important in postgraduate medical e-learning, and grouped these into six domains. The domains also provided a model framework for educators involved in drafting e-learning strategies or evaluating e-learning initiatives. The content domain is the most widely described and discussed domain of the model, and we discuss this in detail below followed by the limitations of our review.

\section{The content domain}

Perhaps the most important part of e-learning is the content, which was emphasized in all articles reviewed. Content is the heart of e-learning, and the design merely delivers content. A common pitfall is developing elearning simply for the sake of using a new technology. Instead of making e-learning technology-centred, developers should subscribe to a learning theory to ensure the design is guided by pedagogical principles [14]. Mayer described the cognitive theory of multimedia learning, based the CLT [17]. CLT aims to develop instructional design guidelines based on a model of human cognitive architecture [65]. CLT states that working memory is limited in its capacity to selectively attend to and process incoming sensory data. This theory is concerned with the way in which a learner focuses and uses cognitive resources during learning and problem solving. It suggests that for an instruction to be effective, it must be designed in a way that does not overload the mind's capacity for processing information [40]. Based on this theory, Mayer defined a set of principles, which describe the effect of different design techniques on learning. These principles form guidelines for using multimedia in a learning environment. In the content domain, we found 20 of 36 articles tested or recommended one or more of Mayer's principles. Because the current literature pays so much attention to these principles, we considered them to be the foundation of the content domain [18].

Not all authors agreed with all of these principles. For example, Yavner et al. [53] proposed giving the learner maximum control, in contradiction to Mayer's assertion that giving control to learners yields no benefit because learners may have too many options [17]. Curry et al. [47], Mhouti et al. [58], and Posel et al. [66] also highlighted the importance of learner-centred e-learning and supported individualized, rather than standardsbased e-learning. Therefore, consensus on the principles of the content of e-learning is lacking.

\section{Limitations}

The major limitations of this review pertain to the methods. We performed an integrative review instead of a systematic review or meta-analysis, because the majority of published studies related to postgraduate medical education did not meet the parameters required for a systematic review. The major limitation of integrative reviews is the potential for bias from the inclusion of non-peer-reviewed information or lower-quality studies. Although Cook et al. [50] conducted a metaanalysis, it was limited to a few domains in e-learning. However, the literature from which the authors drew their conclusions was largely consensus-based.

The second limitation was the fast-changing technology that threatens to render our results obsolete. Elearning is rapidly changing the landscape of medical education and is developing faster than research can evaluate it [67]. This pace of change is a limitation of our review because research is always one step behind technology [67]. Examples of these fast changes are two disruptive innovations in medical education: Massive Open Online Courses and social media on mobile devices [68]. Both impact on e-learning and might dramatically change the education landscape [69]. In this landscape, it is almost impossible to evaluate an innovation properly before it is already outdated. In addition, social media is expected to become important to the collaboration domain of e-learning [70].

Despite these limitations, we believe that our sixdomain Postgraduate ME Model will generate discussion and increase the quality of new e-learning courses. Our e-learning model could be interpreted as a general framework rather than postgraduate-specific, although we have not provided evidence to extend it to other settings, due to the limitation in our search strategy. We have limited the search, to target our audience as good the literature allowed us. Clark et al. clearly states that the target audience should be as specific as possible $[9,10]$. The articles represented in this review were selected with focus on postgraduate learners; further analysis will be required to determine the applicability of our Postgraduate ME Model to other audiences. Even if e-learning developers reject our model, we feel that it is better to have reasons for not using a model than to have no model at all [71].

\section{Conclusion}

In summary, our Postgraduate ME Model aimed to provide a practical framework that can be used to build postgraduate medical e-learning programs that are learner centred, interactive, well planned and designed, based on cognitive load theory, and easy to maintain. Elearning should be about the learner, not the technology. Our proposed model may guide e-learning designers who are developing quality e-learning targeted to postgraduates in medicine. Our six-domain model is unique in that it combines the technical requirements from industry standards with the critical aspects of content and interaction from learning theories. 
The next step is for research to validate these domains with international experts to determine if they are beneficial to postgraduate real-world e-learning. It would be interesting to know if postgraduate e-learning experts agree with our description of qualitative e-learning, based on their experience. Another important question is whether a model such as this could actually be used in practice when developing e-learning platforms. Ultimately, we would like to know whether e-learning based on our Postgraduate ME Model will reproducibly improve learner motivation.

\section{Abbreviations}

CLT, Cognitive load theory; ISO, International standardization organization; Postgraduate ME Model, Postgraduate Medical Education Model

\section{Acknowledgements}

We wish to thank all authors of the articles used for our study, for their great and inspiring work.

\section{Funding}

There was no funding for this study.

\section{Availability of data and materials}

The dataset supporting the conclusions of this article is available in the Postgraduate ME Model repository, http://ideact.nl/memodel.

\section{Authors' contributions}

RL participated in the study design, search, data analysis, and the learning model design. MW was the second reviewer of the search results, drafted the manuscript, and participated in the data evaluation. EN revised the manuscript, added the background data, and participated in the interpretation of results. JK designed the search strings and coordinated the search itself. FS participated in the study design, coordinated the study, was the third reviewer of the data, and revised the manuscript. All authors read and approved the final manuscript.

\section{Authors' information}

R.A. de Leeuw, MD, is a PhD student at the Athena Institute for Transdisciplinary Research of the VU University in Amsterdam, the Netherlands, and senior house officer in obstetrics and gynecology. His primary interest is digital education innovations and minimally invasive surgery.

$\mathrm{M}$. Westerman, MD, PhD, is a senior medical education researcher at the VUMC School of Medical Sciences in Amsterdam, the Netherlands, and resident in internal medicine. His main research interests are transitions within medical education, professional identity development, generic competencies, and postgraduate medical education.

E. Nelson, MD, PhD, is a physician-scientist at Stanford University School of Medicine. Together with R.A. de Leeuw and collaborators, he co-developed the Cholera Outbreak Training and Shigellosis Program. He is now working on digital innovations for e-learning and novel android-based methods to combat infectious disease outbreaks.

J.C.F. Ket is a medical information specialist at the Medical Library at VU University in Amsterdam, the Netherlands. He specializes in search strategies and methodology variations for reviews and literature questions.

F. Scheele, MD, PhD, is Professor in Health Systems, Innovation, and Education at the Athena Institute for Transdisciplinary Research at the VU University in Amsterdam, the Netherlands. His expertise is in postgraduate education, curriculum development, and social responsiveness.

\section{Competing interests}

The authors report no competing interests, financially or otherwise.

\section{Consent for publication}

Not applicable.

\section{Ethical approval and consent}

Not applicable.

\section{Author details}

Athena Institute for Trans-disciplinary Research, VU University Amsterdam, De Boelelaan 1118, Amsterdam $1081 \mathrm{HZ}$, The Netherlands. ${ }^{2} \mathrm{VUmc}$, School of Medical Sciences, Amsterdam, The Netherlands. ${ }^{3}$ Division of Pediatric Infectious Diseases, Department of Pediatrics, Stanford University School of Medicine, Stanford, USA. ${ }^{4}$ VU University Amsterdam, University Library, Amsterdam, The Netherlands.

Received: 17 July 2015 Accepted: 11 June 2016

Published online: 08 July 2016

\section{References}

1. Allen IE, Seaman J. Going the distance: Online education in the United States, 2011. The Sloan Consortium: Organizations Committed to Quality Online Education; 2011.

2. Sandars J, Schroter S. Web 2.0 technologies for undergraduate and postgraduate medical education: an online survey. Postgrad Med J. 2007; 83(986):759-62.

3. Curran VR, Fleet L. A review of evaluation outcomes of web-based continuing medical education. Med Educ. 2005;39(6):561-7.

4. Jwayyed S, Stiffler KA, Wilber ST, Southern A, Weigand J, Bare R, Gerson LW. Technology-assisted education in graduate medical education: a review of the literature. Int J Emerg Med. 2011;4(1):51-64.

5. Childs S, Blenkinsopp E, Hall A, Walton G. Effective e-learning for health professionals and students-barriers and their solutions. A systematic review of the literature-findings from the HeXL project. Health Info Libr J. 2005;22 Suppl 2:20-32.

6. Cook DA, Dupras DM. A practical guide to developing effective web-based learning. J Gen Intern Med. 2004;19(6):698-707.

7. Maggio LA, Tannery NH, Chen HC, Cate O, O'Brien B. Evidence-Based Medicine Training in Undergraduate Medical Education. Acad Med. 2013;88(7):1022-8.

8. Ruiz JG, Mintzer MJ, Leipzig RM. The impact of E-learning in medical education. Acad Med. 2006;81(3):207-12.

9. Clark RC, Mayer R.E. E-Learning and the Science of Instruction: Proven Guidelines for Consumers and Designers of Multimedia Learning. 3rd ed. San Francisco: Pfeiffer; 2011.

10. Cook DA, Ellaway RH. Evaluating technology-enhanced learning: A comprehensive framework. Med Teach. 2015;37(10):961-70.

11. Hung DWL, Chen D-T. Situated Cognition, Vygotskian Thought and Learning from the Communities of Practice Perspective: Implications for the Design of Web-Based E-Learning. EMI Educ Media Int. 2001;38(1):3-12.

12. Marshall S. E-learning standards: Open enablers of learning or compliance strait jackets. Beyond the comfort zone: Proceedings of the 21st ASCILITE Conference. 2004:596-605.

13. Jonassen DH. Learning to solve problems: An instructional design guide. 1st ed. San Francisco: Pfeiffer; 2004. p. 1-10.

14. Koohang A, Harman K. Open source: A metaphor for e-learning. Inf Science J. 2005:8:75-86.

15. Schmidt HG, Van der Molen HT. Constructivist, Problem-Based Learning Does Work: A Meta-Analysis of Curricular Comparisons Involving a Single Medical School. Educ Psychol. 2009;44(4):227-49,

16. Ellaway R, Masters K. AMEE Guide 32: e-Learning in medical education Part 1: Learning, teaching and assessment. Med Teach. 2008;30(5):455-73.

17. Sweller J. Cognitive load during problem solving: Effects on learning. Cogn Sci. 1988;12(2):257-85.

18. Mayer RE. The Cambridge handbook of multimedia learning. 2nd ed. Cambridge: Cambridge University Press; 2014.

19. Singh H, Reed C. Demystifying e-learning standards. Ind Commer Train. 2002;34(2):62-5.

20. Olson CA, Shershneva MB. Setting quality standards for web-based continuing medical education. J Contin Educ Health Prof. 2004;24(2):100-11.

21. Marques CG, Noivo J, Verissimo M. e-QUAL: e-Learning with Quality. Proposal for an Evaluation Model on the Quality of e-Learning Courses. In Mendes AJ, Pereira I, Costa R, Editors. Computers and Education. Towards Educational Change and Innovation. London: Springer; 2008. p. 83-90.

22. Caramihai M, Severin I. eLearning Tools Evaluation based on Quality Concept Distance Computing. A Case Study. Int J Innov Res Sci Eng Technol. 2009;3(5):438-42.

23. Stracke CM. Quality Development and Standards in e-Learning: Benefits and Guidelines for Implementations. Proceedings of the ASEM Lifelong Learning Conference: e-Learning and Workplace Learning Bangkok (Thailand). 2009. 
24. Ehlers UD, Goertz L, Hildebrandt B, Pawlowski JM. Quality in e-learning: use and dissemination of quality approaches in European e-learning: a study by the European Quality Observatory. Cedefop Panorama series. 2006 (116).

25. Little BB. The Use of Standards for Peer Review of Online Nursing Courses: A Pilot Study. J Nurs Educ. 2009;48(7):411-5.

26. Masters K, Ellaway R. e-Learning in medical education Guide 32 Part 2: Technology, management and design. Med Teach. 2008;30(5):474-89.

27. Pawlowski JM. The quality adaptation model: adaptation and adoption of the quality standard ISO/IEC 19796-1 for learning, education, and training. J Educ Techno Soc. 2007;10(2):3-16.

28. Zhang W, Cheng YL. Quality assurance in e-learning: PDPP evaluation model and its application. Int Rev Res Open Dis. 2012;13(3):66-82.

29. Chan CH, Robbins LI. E-Learning Systems: Promises and Pitfalls. Acad Psychiatry. 2006;30(6):491-7.

30. Abdous M. E-learning quality assurance: a process-oriented lifecycle model. Qual Assur Educ. 2009;17(3):281-95

31. Cooke M, Irby DM, O'Brien BC. Educating physicians: a call for reform of medical school and residency. J1st ed. San Francisco: Jossey-Bass Imprint; 2010.

32. Whittemore $R$, Knafl K. The integrative review: updated methodology. J Adv Nurs. 2005;52(5):546-53.

33. Harvey L, Green D. Defining Quality. Assess Eval High Educ. 2006;18(1):9-34.

34. Editor. ACCME about us. 2013. http://www.accme.org/about-us. Accessed 11 May 2014.

35. Al-Jewair TS, Azarpazhooh A, Suri S, Shah PS. Computer-assisted learning in orthodontic education: a systematic review and meta-analysis. J Dent Educ. 2009;73(6):730-9.

36. Mastrangelo G, Fadda E, Rossi CR, Zamprogno E, Buja A, Cegolon L. Literature search on risk factors for sarcoma: PubMed and Google Scholar may be complementary sources. BMC Res Notes. 2010;3:131.

37. Alexander LK, Horney JA, Markiewicz M, MacDonald PDM. 10 Guiding principles of a comprehensive Internet-based public health preparedness training and education program. Public Health Rep. 2010;125 Suppl 5:51-60.

38. Gordon M, Chandratilake M, Baker P. Low fidelity, high quality: a model for e-learning. Clin Teach. 2013;10(4):258-63.

39. Sowan AK, Jenkins LS. Use of the seven principles of effective teaching to design and deliver an interactive hybrid nursing research course. Nurs Educ Perspect. 2013;34(5):315-22.

40. Sorden SD. A cognitive approach to instructional design for multimedia learning. Informing Sci J. 2005;8:263-79.

41. Raymond M, Iliffe S, Pickett J. Technology-enhanced learning. Educ Prim Care. 2012;23(5):458-9.

42. Lau KHV. Computer-based teaching module design: principles derived from learning theories. Med Educ. 2014;48(3):247-54.

43. Garde S, Heid J, Haag M, Bauch M, Weires T, Leven FJ. Can design principles of traditional learning theories be fulfilled by computer-based training systems in medicine: The example of CAMPUS. Int J Med Inform. 2007;76(2-3):124-9.

44. Casebeer L, Kristofco RE, Strasser S, Reilly M, Krishnamoorthy P, Rabin A, Zheng S, Karp S, Myers L. Standardizing evaluation of on-line continuing medical education: physician knowledge, attitudes, and reflection on practice. J Contin Educ Health Prof. 2004;24(2):68-75

45. Maor D, Volet S. Interactivity in professional online learning: A review of research based studies. Int J Educ Techno. 2007;23(2):269-90.

46. Bangert AW. The seven principles of effective teaching: a framework for designing, delivering, and evaluating an internet-based assessment course for nurse educators. Nurse Educ. 2005:30(5):221-5.

47. Curry M, Smith L. Twelve tips for authoring on-line distance learning medical post-registration programmes. Med Teach. 2005;27(4):316-21.

48. Knight CL, Sakowski HA, Houghton BL, Laya MB, DeWitt DE. Developing a peer review process for web-based curricula: minting a new coin of the realm. J Gen Intern Med. 2004;19(5):594-8.

49. Chang H-C, Liu C-F, Hwang H-G. Exploring Nursing E-Learning Systems Success Based on Information System Success Model. Comput Inform Nurs. 2011;29(12):741-7.

50. Cook DA, Levinson AJ, Garside S, Dupras DM, Erwin PJ, Montori VM. Instructional design variations in internet-based learning for health professions education: a systematic review and meta-analysis. Acad Med. 2010;85(5):909-22.

51. Wong G, Greenhalgh T, Pawson R. Internet-based medical education: a realist review of what works, for whom and in what circumstances. BMC Med Educ. 2010;10(1):12.

52. Lewis KO, Cidon MJ, Seto TL, Chen H, Mahan JD. Leveraging e-Learning in Medical Education. Curr Probl Pediatr Adolesc Health Care. 2014;44(6):150-63.
53. Yavner SD, Pusic MV, Kalet AL, Song HS, Hopkins MA, Nick MW, Ellaway RH. Twelve tips for improving the effectiveness of web-based multimedia instruction for clinical learners. Med Teach. 2015;37(3):239-44.

54. Mayer RE. Applying the science of learning to medical education. Med Educ. 2010;44(6):543-9.

55. Minasian-Batmanian LC. Guidelines for developing an online learning strategy for your subject. Med Teach. 2002;24(6):645-7.

56. Davids MR, Chikte UME, Halperin ML. Effect of improving the usability of an e-learning resource: a randomized trial. Adv Physiol Educ. 2014;38:155-60.

57. Khoiny FE. Factors that contribute to computer-assisted instruction effectiveness. Comput Nurs. 1995:13(4):165-8.

58. El Mhouti ANA, Erradi M. Development of a Tool for quality assessment of digital learning resources. I J Comp Appl. 2013;64:27-31.

59. Cook DA. Revisiting Cognitive and Learning Styles in Computer-Assisted Instruction. Acad Med. 2012;87(6):778-84.

60. Mounsey A, Reid A. A randomized controlled trial of two different types of web-based instructional methods: One with case-based scenarios and one without. Med Teach. 2012;34(9):654-8.

61. Bluestone J, Johnson P, Fullerton J, Carr C, Alderman J, BonTempo J. Effective in-service training design and delivery: evidence from an integrative literature review. Hum Resour Health. 2013;11:51.

62. Friedlander MJ, Andrews L, Armstrong EG, Aschenbrenner C, Kass JS, Ogden $P$, Schwartzstein R, Viggiano TR. What can medical education learn from the neurobiology of learning? Acad Med. 2011:86(4):415-20.

63. Issa N, Schuller M, Santacaterina S, Shapiro M, Wang E, Mayer RE, DaRosa DA. Applying multimedia design principles enhances learning in medical education. Med Educ. 2011;45:818-26.

64. Short SED, Guillemette J-M, Duncan AM, Kirby F. Defining quality criteria for online continuing medical education modules using modified nominal group technique. J Contin Educ Health Prof. 2010;30(4):246-50

65. Van Merrienboer JJG, Sweller J. Cognitive load theory in health professional education: design principles and strategies. Med Educ. 2010;44(1):85-93.

66. Posel N, Fleiszer D, Shore BM. 12 Tips: Guidelines for authoring virtual patient cases. Med Teach. 2009;31(8):701-8.

67. Triola MM, Huwendiek S, Levinson AJ, Cook DA. New directions in elearning research in health professions education: Report of two symposia. Med Teach. 2012:34(1):15-20.

68. Mehta NB, Hull AL, Young JB, Stoller JK. Just Imagine. Acad Med. 2013; 88(10):1418-23.

69. Liyanagunawardena TR, Williams SA. Massive open online courses on health and medicine: review. J Med Internet Res. 2014;16(8):e191.

70. Hillman T, Sherbino J. Social media in medical education: a new pedagogical paradigm? Postgrad Med J. 2015;91(1080):544-5.

71. Casimiro L, MacDonald CJ, Thompson TL, Stodel EJ. Grounding theories of W(e)Learn: A framework for online interprofessional education. J Interprof Care 2009:23(4):390-400

72. Kim P, Eng TR, Deering MJ, Maxfield A. Published criteria for evaluating health related web sites: review. BMJ. 1999;318:647-9.

73. Sekikawa A, Aaron DJ, Acosta B, Sa E, LaPorte RE. Does the perception of downloading speed influence the evaluation of web-based lectures? Public Health. 2001;115:152-6.

74. Doyle DJ. Web page evaluation in medical education. Can J Anaesth. 2002; 49.997.

75. Jha V, Duffy S. "Ten golden rules" for designing software in medical education: results from a formative evaluation of DIALOG. Med Teach. 2002 24:417-21.

76. Shaw T, Barnet S, Mcgregor D, Avery J. Using the Knowledge, Process, Practice (KPP) model for driving the design and development of online postgraduate medical education. Med Teach. 2015;37(1):53-8. 